\title{
A new experimental device for rapid measurement of the trunk equivalent modulus of elasticity on standing trees
}

\author{
Jean Launay, ${ }^{\mathrm{a},}$, Philippe Rozenberg ${ }^{\mathrm{b}}$, Luc Paques ${ }^{\mathrm{b}}$ and Jean-Marc Dewitte ${ }^{\mathrm{b}}$ \\ ${ }^{a}$ ESEM, 8 rue Léonard de Vinci, 45067 Orléans Cedex 2, France \\ ${ }^{\mathrm{b}}$ INRA Orléans, 45160 Ardon, France
}

(Received 15 July 1999; accepted 4 January 2000)

\begin{abstract}
A new device has been developed in order to determine experimentally the modulus of elasticity of standing trees. Following preliminary trials on aluminum and steel beams, its performances have been compared to the one of another equipment built according to the model proposed by Koizumi (1987). Large-scale trials were then carried out on Douglas-fir and larch plantations of 72 and 292 trees, respectively. Results showed that the new device described here allowed rapid assessments of the mechanical characteristics presented by populations of rather young trees (i.e.: less than 20 years old). Thus, the data obtained with the device can efficiently be included in selection schemes along with other criteria.
\end{abstract}

genetics / modulus of elasticity / standing tree / douglas-fir / larch

Résumé - Un nouvel appareil pour la mesure rapide d'élasticité équivalent des arbres sur pied. Un nouveau dispositif destiné à la mesure du module d'élasticité des arbres sur pied a été mis au point. Après l'avoir testé sur des poutres en acier et en aluminium, il a été comparé à un autre appareillage construit sur le modèle de celui proposé par Koizumi. Des essais à grande échelle sur des plantations de douglas (72 arbres) et de mélèzes (292 arbres) ont montré que ce dispositif permet de mesurer rapidement les caractéristiques mécaniques d'une population d'arbres assez jeunes (moins de 20 ans) et d'effectuer efficacement une sélection en prenant en compte ce critère parmi d'autres.

génétique / module d'élasticité / arbre sur pied / douglas / mélèze

\section{INTRODUCTION}

The use of wood as construction material requires a good knowledge of its mechanical resistance and elasticity in order to avoid breakage problems and to provide enough rigidity to the built structures (for example, Panshin and de Zeeuw [30]). Thus, forest tree selection schemes should include these requirements as criteria for the breeders to be able to provide elite trees selected as young as possible according to their adaptation and growth but also to their wood properties, and especially their mechanical characteristics [43]. Until now, selection methods in the area were mostly based on density measurements that are proved to be indirectly representative of wood mechanical properties [2, 11, 27, 42-44]. In general, density measurements are performed on small wood samples (increment cores) drilled off the trunk in order to prevent damages to the trees. Basic density

* Correspondence and reprints

Tel. 33 238417332; Fax. 33 238417063; e-mail: jean.launay@univ-orleans.fr 
measurement is the most commonly used technique [44]. Each result corresponds to a local value, while one can observe great variations within a given tree [43]. Variations along the radius can be accounted by techniques such as microdensitometry [31]. Other techniques may be used to estimate wood density: the Pilodyn tester is a hand-held instrument which propels a spring loaded needle into the wood. Depth of needle penetration is read directly from the instrument, and is assumed to be well correlated with wood density $[8,13]$. Because wood density can be indirectly measured at low cost with Pilodyn, it is often used in tree breeding studies $[1,6,34,36,37$, $40,41]$. Other data are obtained with the Resistograph, a device intended to measure the power required to drill a hole into a given trunk [7, 32]. However, one can see that, whatever the technique considered, the data obtained remains based on extremely localized measurements. That is why mean density of a single core (or equivalent) is sometimes poorly related with mechanical properties of destructive samples sawn from the trunk [25, 26, 43]. Moreover, this type of data have been shown to be only weakly correlated to the trunk equivalent MOE in bending $\mathrm{MOE}_{\mathrm{eq}}$ [22]. Presumably, one reason that density is a poor predictor in some situations is also that it cannot account for knots in the wood. Therefore systems which cover a vertical range in the stem have a greater opportunity to include some knots in the volume of wood evaluated. Among possible rapid methods, ultrasound (US) propagation speed within tree trunks allows to deduct their $\mathrm{MOE}_{\mathrm{eq}}$ as long as some hypothesis on their densities are considered [4]. Measurement of US propagation speed represent the bases of the Sylvatest [35]. They integrate a larger volume of wood since they can be performed on 2 meter trunk segments. However, no relationship between these measurements and wood MOE was found by Mamdy [25], on 2 meter long butt-logs from the bottom of young Douglas-fir. Similarly, Chantre (pers. com.) and Teyssandier (pers. com) reported no significant correlation between wood MOE and US speed in different species and different types of samples. Another apparatus, Fakopp, using stress wave technique, is also used in some countries [38]. But we found no published information about its ability to measure or indirectly estimate green wood mechanical properties in standing trees.

In general, wood elasticity is analyzed by means of purely mechanical tests. These tests consist in measuring deformations experimentally generated by calibrated forces applied to determined structures of the material to be studied. In the case of standing trees, trunks would represent the structures to be analyzed by the mean of non-destructive methods. Lengthwise bending rigidity of trees has been determined by Vafai and Farshad [39], then by Langbour [20] (on poplars, using cables to pull their trunks). Similarly, Koizumi proposed a specific device to realize the measurements of trunk equivalent MOE [19]. He demonstrated that his method could be used with benefit on Japanese larch and Cryptomeria japonica breeding programs [14-18]. This last method has recently been used at the INRA research center of Orléans [25]. A first set of trials revealed significant correlations between MOE of trunks and MOE estimations performed on destructive samples sawn in the same trees $[26,33]$. Results obtained within the frame of this experiment highlighted a significant clonal effect [26] and good correlations with microdensity data [33]. However, device setup and MOE measurements were time consuming so that only 20 trees could be studied per day. This was considered not satisfactory in order to rapidly screen forest tree populations for breeding programs [26].

Ultimately, MOE measurements will have to be fast and reliable in order to be included as a selection criteria in forest tree breeding schemes. Our goal was to double at least the number of standing trees analyzed per day. The solution we present here relies on a bending test commonly used in laboratories and based on four fulcrums. Its adaptation to standing trees and field conditions required the device to be light and easy to setup. In this paper, we describe the new device, and present the results of preliminary validation tests and first results of one large-scale field experiment.

In the first part of the study, we assess the reliability of the measurement and its relevance for measuring the mechanical properties of individual trees.

In the second part, we assess the performance of the method in genetic field tests.

\section{MATERIALS AND METHODS}

\subsection{Reliability of the measurement and relevance for measuring the mechanical properties of individual trees}

\subsubsection{The starting point: Koizumi's method [14, 19]}

The principle of the MOE measurement method developed for standing trees by Koizumi is schematized (figure 1). An intermediate structure (ABC) is fixed transversely onto the trunk $(\mathrm{T})$ in order to apply a constant bending moment leading to a bow-shaped distortion. The equivalent axial MOE of the trunk is then calculated according to the geometry of the system and to the force developed by the device. This method provided interesting results when it was tested on five clones of Douglasfir [25]. Indeed, good correlation was observed between MOE estimations obtained either on standing trees or on 


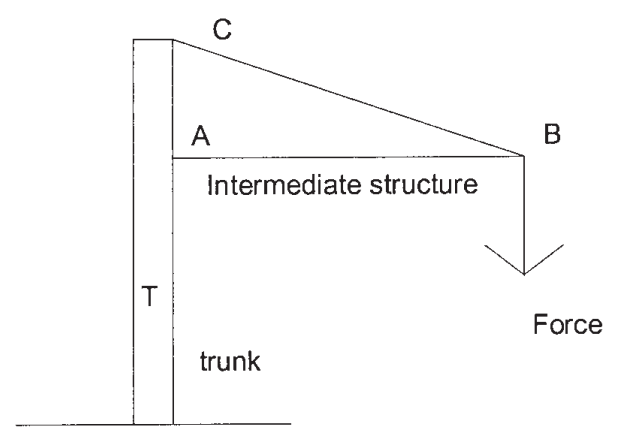

Figure 1. Principle of the experimental device proposed by Koizumi (1990).

destructive wood samples sawn after felling of the trees [25]. Improvement of the system lead us to develop a different device easier to handle and to setup.

\subsubsection{Principle of the bending test}

The principle of the pure bending test is shown figure 2 . This method is routinely used in laboratories to measure the MOE of diverse materials and is a standard to determine the axial MOE of clear wood samples cut along the trunk main axis [29]. The structure to be tested is placed onto two supports $\mathrm{A}$ and $\mathrm{B}$, in order to be subjected to two forces equidistantly applied from the middle of the beam. According to the classical beam theory [3], with an homogeneous material, between these two forces the bending moment and the radius of curvature are constant. Determination of this radius $R$, allows to calculate the MOE of the sample according to the force applied, the shape of the beam and the distances between forces and

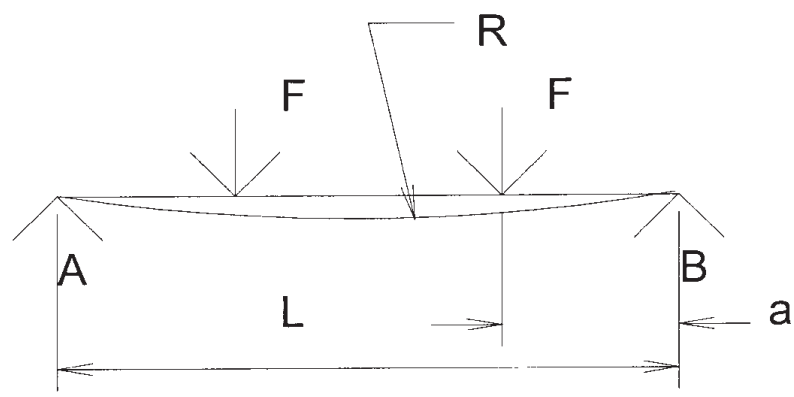

Figure 2. Principle of the pure bending test of an homogeneous cylindrical sample $E=\frac{64 * R^{*} F^{*} a}{\pi d^{4}}$ where $E$ is the sample module of elasticity (Mpa), $F$ is the applied force at each point $(\mathrm{N}), a$ is the distance between the support and the applied load, $d$ is the diameter of the sample, $R$ is the radius of curvature. supports. For a wood beam, the obtained MOE is relative to the $\mathrm{AB}$ direction (figure 2), generally the axial direction.

In this paper, we propose to modify the technique in order to perform global MOE measurements on standing trees. The experimental device we developed for that purpose is composed of two independent units (figure 3). The first one is dedicated to apply the bending force and the second one to measure the resulting deflection of the trunk. The center of the device is routinely placed $1.3 \mathrm{~m}$ above the ground. Diameter of the trunk is determined at this height with an accuracy of $0.5 \mathrm{~mm}$. Pressure is applied at the level of a rectangular aluminum gantry (length: $1.8 \mathrm{~m}$, height: $0.4 \mathrm{~m}$ ). Rigidity of the pressure bar is such that it avoids the device to get in touch with the trunk during assembly and measurements. Fastening of the device onto the trunk is realized by the mean of wide steel contacts in order to avoid wounding of the bark. Pressures are generated by the tightening of two screws separated by $1.2 \mathrm{~m}$ and equipped with two digital sensors used to calibrate the bending forces with an accuracy of $10 \mathrm{~N}$.

Mean curvature of the trunk is then measured $1.3 \mathrm{~m}$ above ground level by the second unit presenting in its middle a distance measurement equipment kept in slight contact with the trunk by the mean of a weight located at

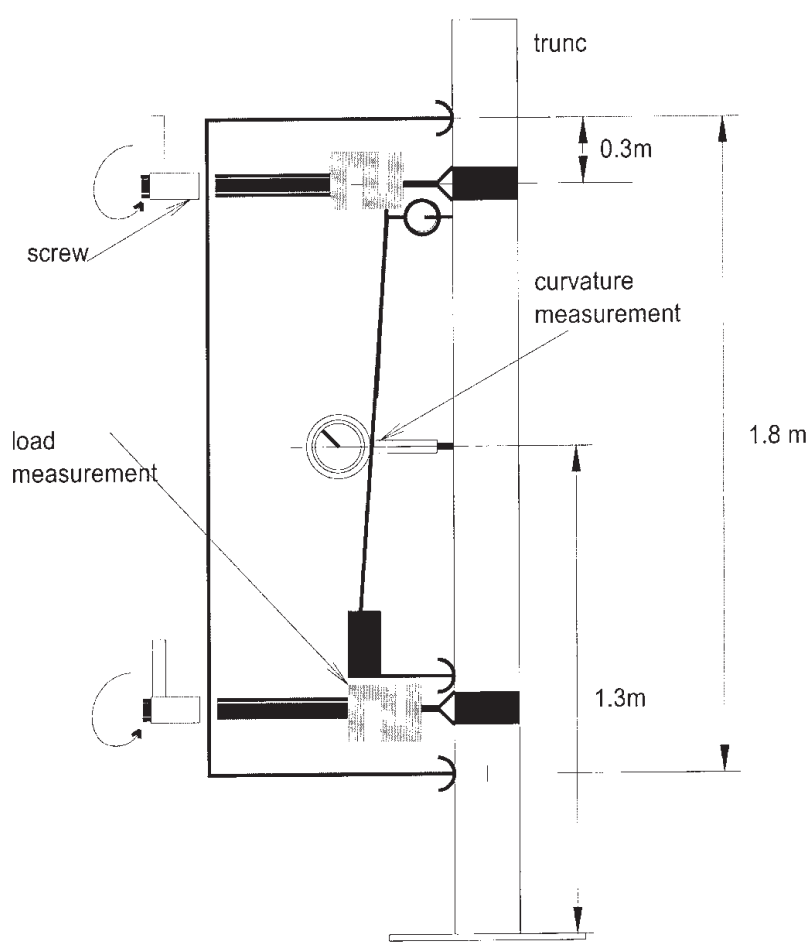

Figure 3. Schematic description of the new device based on pure bending test. Loading unit/displacement measuring unit. 
the bottom of the leaning unit. Deformations produced by the device are detected with an accuracy of $10 \mu \mathrm{m}$. More detailed description of the device is in Dewitte [10]. Considering that the above hypothesis are valid in this case, the obtained measure is the bending equivalent of the axial trunk MOE. Trees or genetic entries are ranked according to the standing tree $\mathrm{MOE}_{\mathrm{eq}}$. The same trees and genetic entries are also ranked according to MOE measured on boards or samples cut off the same trees felled and dried. Both rankings are compared and expected to be closely related.

\subsubsection{Testing of the device}

The device was tested on four experiments:

\subsubsection{Metallic beams}

We used one steel and one aluminum beam, in the laboratory. The objective was to test the effectiveness of the device for measuring MOE of known samples.

\subsubsection{Standing trees}

We used some black pine trees located at the INRA research station, Orléans. The objective was to compare Koizumi's device built at INRA Orléans $[25,26]$ with the new device. The same measurements were performed with both devices on the same trees.

\subsubsection{Comparison with standard destructive methods}

We used one Douglas-fir clonal field test (same as in $[26,33])$. The objectives were to compare tree and clone ranking for trunk MOE estimated with the device, and dry wood MOE measured on destructive samples sawn in the same trees after felling.

The Douglas-fir sample includes 72 trees and 19 different clones $[10,26]$. Trees were 17 years old at the time of the experiment. Three to four individuals were selected per clone in order to present the greatest variability with regard of the diameter of their trunks. Measurements separated by a complete reset of the device were repeated three times on the same axis. The device was then rotated according to a $90^{\circ}$ angle and measurements were repeated as before in order to take into account the non axisymmetry of trunk cross-sections. Thereafter, 29 trees corresponding to 8 different clones were felled and sawn into boards. Three boards of $1.7 \mathrm{~m}$ were produced from each tree so that their middle was approximately located $1.3 \mathrm{~m}$ above the ground. Each board was dried in a steamroom during some weeks with a permanent monitoring of their wood water content. Then they were tested in order to determine their respective MOE. Mechanical characteristics of the dry wood were further analysed. Four

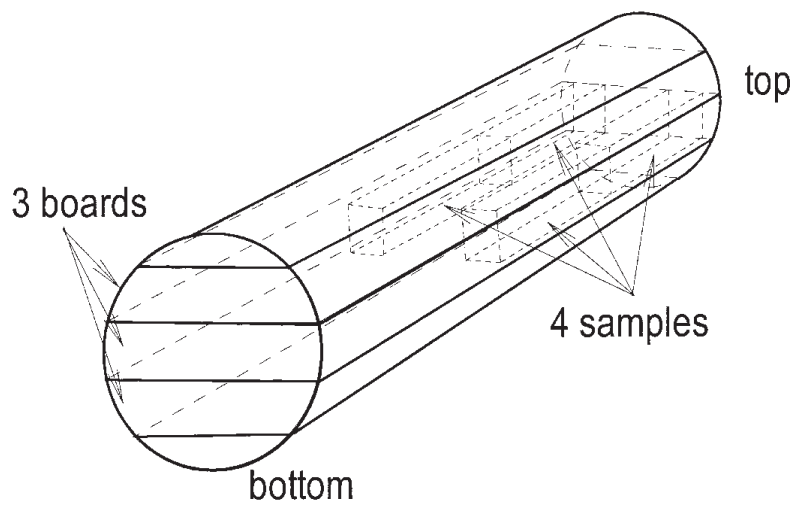

Figure 4. Boards and samples in the tested trunk part.

smaller samples free of knots (figure 4) obtained from both upper and lower parts of each board were analyzed according to the vibration test described by Haines et al. [12]. Indeed, the author showed that the test provides results similar to those obtained with the pure bending test. The strong correlation between the vibration test and the bending test was also reported by Dechalotte [9] on the Douglas-fir clonal sample.

\subsection{Performance of the method in genetic field tests}

Using his device, Koizumi and colleagues [15-18] found significant differences among genetic entries in Japanese larch. Our goal was to test for the existence of genetic effect for trunk MOE estimated with our device.

For that we used two samples:

- The Douglas-fir clonal test previously described (2.1.3.3);

- One large hybrid larch progeny field test (complete description of the experiment can be found in Leroux [23]).

The objectives were:

- to verify that the new method allows a significant statistical resolution of the different genetic entries;

- to compare genetic units ranking for trunk MOE and for density measurements made on the same trees in the frame of a previous study [23];

- to test the utility of the new device for large scale MOE measurements on standing trees.

The plant material is composed of 292 trees corresponding to 28 families of hybrid larch (Larix decidua $\times$ L. kaempferi). Trees were 16 years old at the time of 
measurement. Their diameter averaged out to $18.1 \mathrm{~cm}$ with extreme values of 11.3 and $21.6 \mathrm{~cm}$. In the experiment, measurements were repeated four times according to a single axis. As before, they were separated by a complete reset of the distance measurement equipment.

\section{RESULTS AND DISCUSSION}

\subsection{Testing of the device}

\subsubsection{Metallic beams}

In a first approach, the device we developed was tested on square section of steel and aluminum beams that presented well-known MOE. Indeed, the steel beam was calibrated so that its rigidity corresponded to that of a tree of MOE $8000 \mathrm{Mpa}$ and diameter $200 \mathrm{~mm}$. The aluminum beam corresponded to a tree of MOE $8000 \mathrm{Mpa}$ and diameter $85 \mathrm{~mm}$. In the case of the steel beam, displacements of $0.35 \mathrm{~mm}$ were observed as a result of a force $\mathrm{F}$ of $4000 \mathrm{~N}$ (figure 2). For both calibrated beams, we were able to verify that the MOE measured with the new device were accurate and corresponded to the one expected (i.e.: $207000 \mathrm{Mpa}$ and $69500 \mathrm{Mpa}$, respectively).

Measurement incertitude:

Being given that the data involved in MOE calculation for metallic beams are at least $99 \%$ accurate, most of the incertitude that we observed was linked to the measurement of the radius of curvature (i.e.: $3 \%$ ). If trees are considered, an additional error may arise from diameter measurements performed on trunks which are hypothesized to be circular. In that case, a simple calculation shows that the incertitude related to the radius value acts four times on the one calculated for the modulus (see legend of figure 1). Thus, MOE measurement incertitude increases as tree diameter decreases (e.g.: $2 \%$ incertitude for a diameter of $100 \mathrm{~mm})$. In conclusion, the device should routinely allow MOE determinations of standing tree with an accuracy reaching at least $95 \%$ as long as its trunk shape is presumed circular.

\subsubsection{Standing trees}

In a second approach based on a few sample trees, we compared the device we have developed to the version of Koizumi's apparatus built at INRA Orléans [26]. Under normal conditions of use, maximum incertitude is $5 \%$, that is the sum of the radius of curvature incertitude (3\%) and of the diameter incertitude $(2 \%)$.

Some results showed a better relationship between the applied force and the displacement for the new device: Rsquare was 0.79 for the new device, while it was 0.72 for
Koizumi's. The force-displacement curve was found linear by Mamdy [25], Dewitte [10] and Dechalotte [9] using both prototypes of the rigidimeter.

Thereafter, repeated measurements performed on the same trees with the new device revealed its constancy and reliability. Results also showed that the state of the bark surface did not have significant effects on the data obtained.

\subsubsection{Comparison with standard destructive methods}

We present here how does the in situ measurements in green wood correlate with the dry wood measurements, being given the possible confusing effects of moisture content and also the problems of samples position in the tree, and of samples geometry and structure.

Moisture content was determined just after felling of the trees and averaged out to $94 \%$. In general, wood MOE decreases when relative humidity percentage increases until saturation point is reached. Then it remains quite constant $[5,21]$. Thus, discrepancies between samples presenting different $\mathrm{MOE}$ at the hygroscopic equilibrium remain rather constant once the saturation point is reached. In consequence, MOE rankings should not be affected by the type of material used for their determinations (i.e. tree trunks, boards or smaller samples). At the end, small samples were cut off from wood without any apparent defect, while trunks include knots and other defects, which tend to decrease wood MOE [3]. For this reason, smaller samples should generate higher MOE values.

Mean MOE values obtained for each tree and clone are summarized (figures $5 a-c$ ). At the tree level (figure $5 b$ ), correlation coefficient was moderate: $r=0.58(p=$ 0.0011 ) between trunk $\mathrm{MOE}_{\mathrm{eq}}$ and central board MOE, and $r=0.54(p=0.0019)$ between trunk $\mathrm{MOE}_{\mathrm{eq}}$ and the mean of boards MOE. One may observe that only one tree is accountable for a large part of this coefficient of correlation. At the clone level (figure 5c), correlation between trunk $\mathrm{MOE}_{\mathrm{eq}}$ and destructive samples MOE was stronger: it was: $r=0.74, p=0.04$ (with central board MOE) and $r=0.79, p=0.02$ (with the mean of 2 boards MOE). The genetic entry level is the important one for tree breeders, because selection is conducted at the clone, family or provenance level, but not at the tree level. Thus ranks appeared well conserved from a breeder point of view when measurements performed on boards and small samples are considered, despite the differences for sample size, geometry, structure and moisture content. According to the results of these tests, we consider that MOE measurements performed on standing trees with the new device were reasonably validated for its use by tree breeders. Based on these preliminary results, the new 

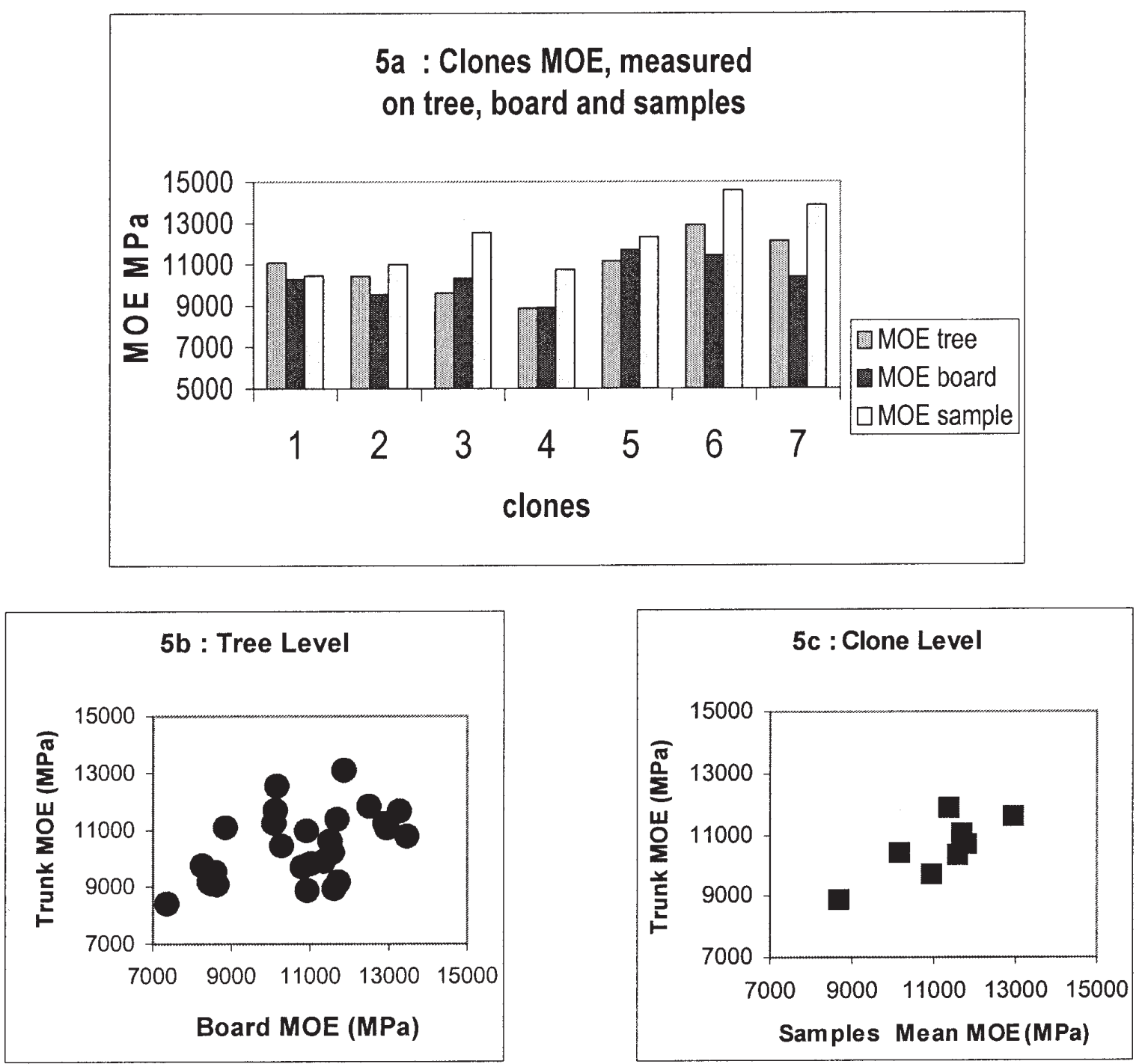

Figure 5. Comparison of the different MOE measuring methods. MOE were measured using trees, boards or small wood samples as starting material.

device was used to test the mechanical performances of genetically identified populations among two different species (i.e.: Douglas-fir and hybrid larch).

\subsection{Performance of the method in genetic field tests}

Douglas-fir populations:

This experiment aimed at knowing if there was significant clonal variation for the trunk MOE measured with the new device. These variations sources may interfere with between-tree and between-clone variation.

Analysis of variance of MOE measurements performed on standing trees.

Analysis of variance allows to pinpoint the eventual effect of different factors on a selected variable. As in [26] with Koizumi's machine, analysis of the MOE estimated at the tree level revealed a highly significant clonal effect characterized by a $F$ test value of 6.3 (table I). As in [26], MOE values did not appear to be correlated to the diameter of the trunk at the tree level 
Table I. Variance analysis at clonal level. Model $\mathrm{MOE}_{j k}=$ mean + clone $_{i}+$ tree $_{j}$. clone $e_{k}+$ eps $_{i j k}$.

\begin{tabular}{|c|c|c|c|c|c|c|}
\hline Factor & Source of variation & MSD & DOF & MS & $F$ & $P(\%)$ \\
\hline $\mathrm{cl}$ & & $0.1774 \mathrm{E}+09$ & 18 & 9854345.0 & 6.3 & 0.00 \\
\hline \multirow[t]{4}{*}{ tree.cl } & & $0.3615 \mathrm{E}+09$ & 53 & 6821459.5 & 4.3 & 0.00 \\
\hline & Residual standard deviation & $0.1131 \mathrm{E}+09$ & 72 & 1571238.2 & & \\
\hline & Variance of the model & $0.5389 E+09$ & 71 & 7590360.5 & 4.8 & 0.00 \\
\hline & Total variance & $0.6520 \mathrm{E}+09$ & 143 & 4559753.5 & & \\
\hline
\end{tabular}

$(r=-0.08, p>0.05)$ or at the clone level $(r=-0.22$, $p>0.05)$. At the clone level, MOE ranged between 8880 and $12890 \mathrm{MPa}$ and averaged out to $10881 \mathrm{MPa}$ with a clonal coefficient of variation of $12.7 \%$ (in [25], at the clone level, for 5 clones composed of slightly younger trees, trunk MOE ranged from 8400 to $9500 \mathrm{MPa}$ ). On all experiments conducted with both versions of the rigidimeter, no relationship was observed between tree diameter and trunk $\mathrm{MOE}_{\mathrm{eq}}$.

Because of the good correlation at the clone level between trunk MOE and destructive sample MOE, we conclude that the newly developed device represents thus a mean to rank clones according to their mechanical properties.

In addition, the use of the new method allowed to increase significantly the number of measurements. Indeed, up to 50 trees could be analyzed per day as compared to 20 using Koizumi's method under the same conditions. Finally, these results allowed us to plan its routine use for larger field tests.

Larch populations:

The newly developed method was applied to 292 trees corresponding to 28 families of hybrid larch (Larix decidua $\times$ L. kaempferi).

Repeatability and timing of the measurements

For each tree, the four replicated deformation measurements and calculated MOE were highly reproducible as indicated by a replication coefficient of 0.994 . With regard to the rank of each individual determined either according to distortion measurements or to MOE estimations, Kendall's concord coefficient reached 0.987 $(p<0.001)$ and $0.951(p<0.001)$, respectively. In addition, these coefficients increased slightly to reach respectively $0.993(p<0.001)$ and $0.970(p<0.001)$ if one considers only the three last measurements.

Setup of the device on previously marked and trimmed trees, measurements of both diameter at $1.3 \mathrm{~m}$ and MOE, as well as dismantling and moving to the next tree required 7 to 8 minutes for a team of 3 people. That means that, in good conditions, for well trained techni- cians, it was possible to measure significantly more than 50 trees per day.

Analysis of variance of the MOE measurements on larch.

Highly significant differences were observed among larch families $(F$ test $=3.3, p<0.01)$ and blocks $(F$ test $=$ 2.4, $p=0.01)$. Mean MOE values determined at the family level were comprised between 5507 and $9148 \mathrm{Mpa}$. In addition to a great individual variability (coefficient of variation $=23 \%$ ), we detected important differences between families (coefficient of variation $=$ $11.7 \%$ ).

A significant relationship was found between trunk MOE and wood density at the family level: $r=0.68(p>$ 0.001 ). The same type of result was frequently found for relationships between clear sample $\mathrm{MOE}$ and sample density (for example [2, 24, 27, 28, 30, 44]. It was more recently found for trunk MOE and density of samples sawn in the trunk $[14,26]$.

Detailed results about genetic analysis of the data, along with other wood properties, will be published in another paper.

\section{CONCLUSION}

The accuracy of the device we have developed to measure MOE was confirmed by the results of preliminary tests on metallic beams. Thereafter, we have shown that measurements of MOE could be performed on standing trees and allowed to rank these trees in the same order than destructive techniques based on the use of boards and smaller samples cut off the felled trees and dried. We have shown that, like Koizumi's machine, the device was able to reveal the existence of significant genetic variation among 2 types of genetic entries (clones and families) for 2 important forest tree species (Douglas-fir and hybrid larch). The new device provides highly reproducible data in a short time. The unit appears reliable to measure trunk deformations even in the case of lowquality surfaces related to bark shape. High pressures can 
be developed onto the trunk by the unit in so far it is used during the tree resting period. However, no major damage was noticed on the trees. Finally, the device is compact and composed of a small number of parts. Its weight has been slightly lowered without any effect on its accuracy. It is then easier to handle and more flexible. Since then, minor technical improvements have been realized in order to make the device use easier. Other secondary improvements are planned and will be realized during the next months in order to produce the definitive apparatus.

Measurable tree has a diameter at breast height ranging from less than $10 \mathrm{~cm}$ to more than $20 \mathrm{~cm}$. There is no need to fell the tree, nor to collect even a single increment core. It is then especially interesting for all forest tree scientists who need global and not too much time consuming information about mechanical properties of the most valuable part of the stem. Finally, the device is a quite cheap equipment compared to most machines that are used for non-destructive testing of wood quality.

Acknowledgements: We want to thank Frédéric Millier and Michel Vallance, Research Technicians at INRA Orléans, and Frédéric Tardy, Technician at Orléans University, for their help all along this study. We also want to thank the 2 anonymous reviewers, who helped to considerably improve the manuscript.

\section{REFERENCES}

[1] Adams T., Aitken S., Balduman L., Schermann N., Pilodyn repeatability study, in Pacific Northwest Tree Improvment Research Cooperative Annual Report, Oregon State University, Corvallis 1992-93, USA (1993) pp. 29-35.

[2] Armstrong J.P., Skaar C., de Zeeuw C., The effect of specific gravity on several mechanical properties of some world woods, Wood Sci. Tech. 18, 2 (1984) 137-146.

[3] Bodig J., Jayne B.A., Mechanics of Wood and Wood composites, Van Nostrand Reinhold Company, New York, Cincinnati, Toronto, London, Melbourne (1982).

[4] Bucur V., Ondes ultrasonores dans le bois. Caractérisation mécanique et qualité de certaines essences de bois, Doct. ing. INP de Lorraine France (1980).

[5] Carrington, The elastic constants of spruce as affected by moisture content, Aeron. J. 26 (1922) 462.

[6] Chantre G., Sutter-Barrot E., Gouma R., Bouvet A., De l'intérêt de l'utilisation du Pilodyn dans l'étude de la qualité du bois : application à l'épicéa commun et à l'épicéa de Sitka, Annales AFOCEL (1992) pp. 145-177.

[7] Chantre G., Rozenberg P., Can drill resistance profiles (Resistograph), lead to within-profile and within-ring density parameters in Douglas-fir wood, in proceedings Timber Management Toward Wood Quality and End-Product Value, CTIA/IUFRO International Wood Quality Workshop, August 18-22, 1997, Québec City, Canada (1997) pp. II 41-46.
[8] Cown D.J., Use of the Pilodyn wood tester for estimating wood density in standing trees - influence of site and tree age, Forest Research Institute, New Zealand Forest Service, Bulletin 13 (1981).

[9] Dechalotte F., Étude d'un appareil permettant de mesurer le module d'élasticité des arbres sur pied, Rapport de stage ESEM - INRA Orléans (1996).

[10] Dewitte J.M., Outils et méthode pour l'amélioration génétique des arbres forestiers en milieu naturel : le rigidimètre, Mémoire Ingénieur CNAM Orléans (1998).

[11] Guitard D., Mécanique du bois et composites, Cepadues éditions, France (1987).

[12] Haines D.W, Leban J.M., Herbé C., Determination of Young's modulus for spruce, fir and isotropic materials by the resonance flexure method with comparisons to static flexure and other dynamic methods, Wood Science and Technology, 30 (1996) 253-263.

[13] Hoffmeyer P., The Pilodyn instrument as a non-destructive tester of the shock resistance of wood. in proceedings of the $4^{\text {th }}$ symposium on non destructive testing of wood, Pullman, Washington, USA (1978) pp. 47-66.

[14] Koizumi A., Studies on the estimation of the mechanical properties of standing trees by non-destructive bending test, Bulletin of the College Experiment Forest, Faculty of Agriculture, Hokkaido University 44, 4 (1987) 1329-1415.

[15] Koizumi A., Variability in wood quality of Japanese larch observed by tree bending tests, 19th IUFRO congress, Montreal (1990) p. 7.

[16] Koizumi A., Takada K., Ueda K., Katayose T., Radial growth and wood quality of plus trees of Japanese larch I. Radial growth, density, trunk modulus of elasticity of grafted clones, Mokuzai Gakkaishi 36, 2 (1990) 98-102.

[17] Koizumi A., Takada K., Ueda K., Radial growth and wood quality of plus trees of Japanese larch II. Diameters at breast heights and trunk moduli of elasticity of 18-year-old offspring families, Mokuzai Gakkaishi 36, 9 (1990) 704-708.

[18] Koizumi A., Takada K., Ueda K., Variation in modulus of elasticity among japanese larch from different provenances, Proceedings of the IUFRO working party S2.02-07, Berlin 512/09/1992 (1992) pp. 66-72.

[19] Koizumi A., Ueda K., Estimation of the mechanical properties of standing trees by non-destructive bending tests, Mokuzai Gakkashi 39, 2 (1986) pp. 669-676.

[20] Langbour P., Rigidité de l'arbre sur pied, indicateur de l'élasticité longitudinale du bois, application aux peupliers, thèse INPL Nancy (1989) p. 136.

[21] Launay J., Mudry M., Gilletta F., Étude expérimentale de l'influence du taux d'humidité sur l'élasticité du bois, CR 19 Colloque du GFR, Cepadues Toulouse (1986) pp. 443-452.

[22] Launay J., Nepveu G., Guitard G., Bucur V., Carminati M., Comparaison entre six méthodes d'estimation des constantes élastiques d'un épicéa de Sitka, in proceedings Colloque Scientifique Européen du G.S. Rhéologie du bois, Bordeaux, France (1988). 
[23] Leroux A., Étude de la variabilité génétique du mélèze hybride à travers des caractères du bois, rapport de BTS "Gestion Forestière", INRA Orléans (1998) p. 35.

[24] Littleford T.W., Variation of strength properties within trees and between trees in a stand of rapid-growth Douglas-fir, For. Prod. Lab. Can. Vancouver, Canada (1961).

[25] Mamdy C., Contribution à l'étude du module d'élasticité de troncs d'arbres sur pied ; utilisation en amélioration génétique des arbres forestiers, rapport DEA Matière condensée et diluée, ESEM Orléans, INRA Orléans (1995) p. 47.

[26] Mamdy C., Rozenberg P., Franc A., Launay J., Scherman N., Bastien J.C., Genetic control of stiffness of standing Douglas fir; from the standing stem to the standardised wood sample, relationships between modulus of elasticity and wood density parameters, Part 1, Ann. For. Sci. 56 (1999) 133143.

[27] Nepveu G., La variabilité du bois in le matériau bois, 2nde édition, ARBOLOR, Nancy (1991).

[28] Newlin J.A., Wilson T.R.C., The relation of the shrinkage and strength properties of wood to its specific gravity, USDA Bulletin 676 (1919) pp. 35.

[29] Norme NF 51-008, Bois, Essais de flexion statique, Détermination de la résistance à la flexion statique de petites éprouvettes sans défaut, AFNOR Paris (1987) p. 7.

[30] Panshin A.J., de Zeeuw C., Textbook of wood technology, McGraw Hill Book Co., New York (1980) p. 722.

[31] Polge H., Établissement des courbes de variation de la densité du bois par exploration densitométrique de radiographies d'échantillons prélevés à la tarière sur des arbres vivants, Application dans les domaines technologiques et physiologiques, Thèse de Doctorat, Université de Nancy, France (1966) p. 206.

[32] Rinn F., Schweingruber F.H., Schär E., RESISTOGRAPH and X-ray density charts of wood : comparative evaluation of drill resistance profiles and X-ray density charts of different species, Holzforschung 50 (1996) 303-311.

[33] Rozenberg P., Franc A., Mamdy C., Launay J., Scherman N., Bastien J.C., Genetic control of stiffness of standing Douglas fir; from the standing stem to the standardised wood sample, relationships between modulus of elasticity and wood density parameters, Part 2, Ann. For. Sci. 56 (1999) 145 154

[34] Rozenberg P., Van de Sype H., Genetic variation of the Pilodyn-girth relationship in Norway pine spruce (Picea abies L. (Karst)) Ann. Sc. For. 53 (1996) 1153-1166.

[35] Sandoz J.L., Valorisation des produits forestiers en matériaux de construction, in Proceedings IUFRO-5, 1 (1992) 372.

[36] Schermann N., Étude des paramètres génétiques de trois populations de Douglas vert (Pseudotsuga menziesii (Mirb.) Franco), analyse d'un diallèle $16 \times 16$, conséquences pour la stratégie d'amélioration génétique de l'espèce. Thèse Institut National Agronomique Paris Grignon-INRA Orléans, France, (1994) p. 117.

[37] Sprague J.R., Talbert J.T., Jett J.B., Bryant R.L., Utility of the Pilodyn in selection for mature wood specific gravity in Loblolly pine, For. Sci. 29, 4 (1983) 696-701

[38] Tanaka T., Divos F., Facan T., Evaluation of Residual Bending Strength of Wood with Artificial Defect(s) by Stress Wave, Proc. of the "Annual Meeting of the Japanese Wood Research Society" (1997).

[39] Vafai and Farshad, Modulus of elasticity of wood in standing tree, Wood Sci. 12, 2 (1979) 93-97.

[40] Van de Sype H., Clones (Compte Rendu des premiers résultats des tests INRA 6.352.1, 6.352.2 et 6.351, Document Interne, INRA Orléans, France (1994).

[41] Villeneuve M., Morgenstern E.K., Sebastian L.P., Estimation of wood density in family tests of jack pine and black spruce using the Pilodyn tester, Can. J. For. Res. 17 (1987) 1147-1149.

[42] Zhang S.Y., Effect of growth rate on wood specific gravity and selected mechanical properties in individual species from distinct wood categories, Wood Sci. Tech. 29 (1995) 451465.

[43] Zobel B.J., Van Buijtenen J.P., Wood variation, its causes and control, Springer-Verlag, Berlin (1989) p. 363.

[44] Zobel B.J., Jett B.J., Genetics of Wood Production. Springer-Verlag, Berlin (1995) p. 337. 